\title{
A interpretação de imagens e o Método Documentário'
}

\section{RALF BOHNSACK*}

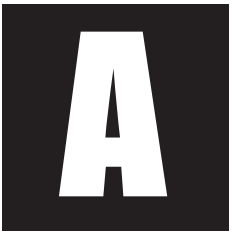

interpretação de imagens obteve até o momento uma importância meramente marginal no âmbito dos Métodos Qualitativos nas Ciências Sociais. Neste sentido, é necessário analisar e tecer considerações sobre alguns motivos responsáveis por essa lacuna. Nesta perspectiva, examinarei a questão de como é possível desenvolver um método próprio das Ciências Sociais, que leve em consideração a singularidade da imagem em contraposição ao texto. Pretendo demonstrar a importância e a necessidade dos Métodos e Teorias da História da Arte, bem como, em certa medida, os da Semiótica na interpretação sociológica de imagens. O método documentário de interpretação, cuja origem remonta à Sociologia do Conhecimento de Karl Mannheim, desenvolve um papel fundamental. Entre outros motivos, este método, próprio das Ciências Sociais, originou-se em um contexto de influência recíproca, com métodos da História da Arte, em particular com a iconologia. ${ }^{2}$

\footnotetext{
* Doutor em Sociologia pela Universidade de Bielefeld e livre docente pela Universidade ErlangenNürnberg. É professor da Universidade Livre de Berlim desde 1990. Alemanha.

1 Texto traduzido do original inédito "Qualitative Methoden der Bildinterpretation und dokumentarische Methode" por Luisa Günther e revisado por Wivian Weller.

2 Para maiores informações sobre o método documentário de interpretação cf. Bohnsack, 2003 e Weller, 2005.
} 
Analisando o desenvolvimento dos métodos de interpretação de imagens no âmbito da pesquisa qualitativa, deparamo-nos com impressões, que, a princípio, parecem um tanto paradoxais. Aparentemente o aprimoramento e a consolidação dos métodos qualitativos nos últimos 25 anos levou, proporcional e concomitantemente, a uma marginalização da imagem. Por um lado, essa situação está relacionada ao fato de que as metodologias qualitativas foram apreendidas de forma radical pela assim denominada "reviravolta lingüística" (linguistic turn - cf. Rorty, 1967). Essa reviravolta lingüística ganhou amplo espaço no campo das Ciências Sociais empíricas em função da já conhecida premissa sobre a 'validade' apresentada primeiramente por Karl Popper (1959) ou seja: "a verdade, quando tiver pretensão à relevância científica, deve apresentar-se na forma de frase observáveis (Beobachtungssätzen) ou frases protocolares (Protokollsätzen)," ${ }^{3}$ ou seja, em um formato textual.

Esta premissa da metodologia convencional foi, não apenas, seguida pela pesquisa qualitativa ou reconstrutiva. Muitas outras conseqüências resultaram dela. Apenas ali, na linguagem, na manipulação verbal por parte dos próprios pesquisados, nos textos produzidos por estes e originários de dados primários, não seria necessária a presença do pesquisador ou observador na transformação desses textos em frases protocolares. Entretanto essa transformação é necessária no âmbito da interpretação de imagens como também na observação participante - o que, por sua vez, gerou dúvidas quanto à validade das imagens como material empírico. A marginalização da interpretação de imagens foi assim mais uma vez corroborada pela radicalização da compreensão da verdade social como textualmente formatada. Nesse sentido, representantes da corrente conhecida como hermenêutica objetiva - uma das mais avançadas no campo das

3 Original: "Wirklichkeit muss, wenn sie wissenschaftliche Relevanz gewinnen will, in Form von Beobachtungssätzen oder Protokollsätzen", also in Form von Texten, vorliegen. 
metodologias qualitativas na Alemanha ${ }^{4}$ - também defenderam a textualização (Textförmigkeit) dos fenômenos culturais, ou seja, da imagem, como, por exemplo, na obra Die Welt als Text (O mundo como texto) de Garz \& Kraimer (1994). Outros representantes da pesquisa social qualitativa criticaram a posição da hermenêutica objetiva (cf. Reichertz, 1992). Mas, ao mesmo tempo, contribuíram para manter alguns aspectos centrais da formatação falada e textual da verdade social. Toma-se de uma maneira "privada", por assim dizer, uma compreensão monológica da mídia imagética em oposição à fala e ao texto, mas não uma compreensão comunicativa. Essa posição é, de certa forma, responsável pela predominância da fala e do texto no campo da pesquisa social empírica.

A respeito deste problema, pode-se concluir que, de uma maneira geral, a pesquisa social qualitativa não conseguiu estabelecer ainda uma diferenciação entre duas formas bem distintas de compreensão da imagem gráfica. Existe uma diferença entre desenvolver uma compreensão sobre (über) a imagem e uma compreensão através (durch) da imagem. Uma compreensão intersubjetiva através da imagem, ou seja, através da mídia imagética, e, portanto, em oposição à mídia falada e textual, permanece ainda tácita, e, respectivamente, sem qualquer fundamentação concreta por parte das metodologias ou teorias da ação (Handlungstheorien). Nesta perspectiva, a compreensão sobre a imagem resulta unicamente da análise dos elementos verbais ou textuais a seu respeito.

Na diferenciação entre a compreensão através da imagem e a compreensão sobre a imagem estão implícitas posições sobre nossas interpretações e ações cotidianas, que se estendem às teorias da ação, do conhecimento, da percepção e dos signos. O fato de compreendermos o cotidiano através de imagens significa que nosso mundo, nossa realidade social não é

4 Sobre a hermenêutica objetiva cf. entre outros: Reichertz, 2004. 
apenas representada de forma imagética, mas também constituída ou produzida dessa forma. William Mitchell (1994: 41) dedicou-se extensivamente a esta questão. Entretanto a constituição do mundo através de imagens pode ser compreendida de dois modos distintos: uma dessas compreensões pressupõe que somente a interpretação do mundo é realizada sobretudo pela via iconográfica; para além dessa compreensão, a constituição do mundo através da mídia imagética pode ser ampliada se levarmos em consideração o fato de que a imagem também possui a qualidade de dirigir a ação (handlungsleitende Qualität der Bilder). No que tange às teorias da ação, da comunicação e do desenvolvimento humano, este último aspecto é amplamente ignorado. No entanto, no nível da compreensão e da aprendizagem, da socialização e da formação (para além das instâncias de comunicação de massa), a imagem desempenha um papel fundamental na orientação de nossas ações práticas. Esse aspecto permanece praticamente despercebido, principalmente no que diz respeito ao fato de que as cenas ou situações sociais são apreendidas sobretudo como 'imagens interiores' (innere Bilder). Estas são apropriadas mimeticamente (cf. Wulf, 1998) e recordadas por meio de imagens.

Em cada signo ou sistema de significados, as imagens estão implícitas. Para cada significante (por exemplo, uma palavra) existe um significado correspondente que não é uma coisa, mas uma imagem interior ou física. $\mathrm{Na}$ semiologia de Roland Barthes, este aspecto é explicado da seguinte forma: "o significado da palavra boi não é o animal boi, mas sua imagem física" ("le signifié du mot boeuf n'est pas l'animal boeuf, mais son image psychique" - Barthes, 1993, p. 1488). De acordo com Alfred Schütz, cada símbolo ou tipologia está fundamentado em "imaginações de sentidos apresentados hipoteticamente" ("imagination of hypothetical sense presentations" Schütz, 1964, p. 3). A compreensão por meio de imagens, quer dizer, por meio de imagens interiores, acontece de forma pré-reflexiva. Trata-se de 
uma compreensão situada em um nível aquém da explicitação abstratolingüística. A compreensão da imagem é realizada por meio do conhecimento implícito ou ateórico, como denominado por Karl Mannheim (1982; cf. Weller et al, 2002). Esses conhecimentos implícitos ou ateóricos estruturam, sobretudo, as ações habituais ou rotineiras. Esse conhecimento é transmitido, por um lado, através de narrações e descrições, ou seja, de forma metafórica e por intermédio de metáforas que representam graficamente as cenas sociais. Entretanto o conhecimento ateórico, o conhecimento sobre o "habitus", é transmitido principalmente através da própria imagem, através da iconicidade. A transmissão do conhceimento ateórico é realizada sobretudo pela linguagem figurativa (Bildlichkeit), no sentido atribuído por Gottfried Boehm, que define linguagem figurativa da seguinte forma: "imagem e fala participam em um mesmo nível da linguagem figurativa" (1978: 447). E esse nível da linguagem figurativa pertence ao domínio do conhecimento implícito.

Neste sentido, a mudança do nível do conhecimento explícito, ou seja, do nível das teorias do senso comum, para o nível do conhecimento implícito ou ateórico é equivalente à distinção tecida por Erwin Panofsky entre iconografia e iconologia. Panofsky, à sua maneira, foi influenciado de modo significativo pelas discussões das Ciências Sociais, particularmente por Karl Mannheim e seu método documentário de interpretação. Neste sentido, a diferença entre interpretação iconográfica e iconológica corresponde à mudança da interpretação imanente para a interpretação documentária apresentada por Karl Mannheim (1952). Esta mudança paradigmática da perspectiva de análise remonta à abertura do questionamento sobre o que (was) para o questionamento sobre o como (wie) como apontado por Heidegger (1986), Luhmann (1990) e pelo próprio Mannheim. Trata-se de uma mudança na formulação da pergunta, ou seja, ao invés de questionar o que são fenômenos ou fatos sociais, o pes- 
quisador deve dirigir suas atenções para a compreensão de como estes são constituídos.

Em Panofsky, a pergunta sobre o quê não se restringe apenas ao nível da iconografia, mas também à fase pré-iconográfica. A relevância sociológica desta diferenciação realizada pelo autor é sobremodo significativa quando Panofsky (1975, p. 38) esboça o caminho a ser seguido pela interpretação, não apenas no campo artístico, mas também no que diz respeito às "vivências cotidianas" (Alltagsleben). Tomando como exemplo uma gesticulação ou movimento de um conhecido, apresenta a seguinte interpretação: O gesto em questão que, num nível "pré-iconográfico" é identificado como a "movimentação do chapéu", só será interpretado como um cumprimento no nível iconográfico de análise. Em termos sociológicos, essa interpretação realizada por Panofsky pode ser caracterizada ainda como "motivos para" (Um-zu-Motiven), no sentido elaborado por Alfred Schütz (1964, p. 21s), ou seja: O conhecido movimenta seu chapéu para cumprimentar. Dirigimonos então - como também faríamos no nível do senso comum - à busca das intenções subjetivas. Quando não estamos lidando com ações institucionalizadas, com ações expressivas de determinados papéis sociais, a interpretação iconográfica permanece metodologicamente insegura, pois está pautada em introspecções e suposições.

A análise iconológica em contraposição à iconográfica, caracteriza-se pela "ruptura com o senso comum", como diria Pierre Bourdieu (1996, p. 269). Diferencia-se, de forma radical, ao deixar de perguntar o que e enfocar o como, ou seja, o modus operandi da produção e, respectivamente, da formação dos gestos. Para Panofsky, "o significado propriamente dito", o "conteúdo" de um gesto (1975, p. 40), sua essência ou mesmo seu sentido documentário (1932, p. 115-118) só pode ser apreendido desta forma. Por intermédio da interpretação iconológica dos gestos, adquirimos "a impressão de que estes contêm modos específicos de existência ... , documenta- 
dos no gesto do cumprimento tanto de forma clara como de forma independente do querer e do saber daquele que cumprimenta, como estaria documentado em qualquer outra manifestação em que pessoas estivessem envolvidas" (idem, p. 115s).

Panofsky também define esse "sentido do ser" (Wesenssinn) como habitus, conceito que foi tomado e desenvolvido posteriormente por Bourdieu (1970), a partir de Panofsky. Habitus enquanto conceito pode referir-se tanto a fenômenos individuais quanto a fenômenos coletivos relativos ao meio social (milieu), por exemplo, o habitus proletário ou burguês. Pode também exprimir um determinado período histórico ou uma geração como o habitus da geração 1968. Pode ainda - e aqui reside propriamente o interesse do autor - ser expressão de todo um período histórico, seja o período Gótico ou a Renascença. De acordo com Panofsky, o sentido iconológico "pode ser apreendido desvelando-se todo e qualquer princípio constituído como base de uma nação, de uma época, de uma classe, de uma crença religiosa ou filosófica, modificado por uma personalidade e condensado em uma única obra" (1975, p. 40).

Para Panofsky a busca do sentido iconológico (ikonologischen Sinngehalt) deve levar em conta o habitus dos produtores de imagens. No entanto é necessário estabelecer uma distinção entre duas dimensões relativas aos produtores de imagens. Por um lado, existem (como eu gostaria de assim chamar) os produtores de imagem que reproduzem (abbildenden Bildproduzentinnen), por exemplo, os fotógrafos ou artistas assim como quaisquer outros que, como produtores, estão situados por detrás das câmeras e participam do registro e da produção posterior da imagem. Por outro, existem os produtores de imagem reproduzidos (abgebildeten Bildproduzentinnen), ou seja, as pessoas, criaturas ou cenas sociais que são os sujeitos da imagem e que atuam diante da câmera. Metodologicamente a complexa relação resultante das duas formas de produção de imagens pode ser 
resolvida com relativa facilidade quando ambos produtores pertencem a um mesmo espaço de experiências, a um mesmo meio social. Por exemplo, quando alguém faz um retrato de sua própria família, quando o pintor retrata alguém de sua própria realidade ou quando o pintor, as pessoas ou cenas retratadas pertencem a um mesmo período histórico. A interpretação iconológica tem por objetivo a constituição de uma via de acesso ao espaço de experiência dos produtores dessas imagens, cuja compreensão do habitus individual e coletivo dos produtores constitui-se como um elemento central. Muito mais complexas, sob o ponto de vista metodológico, são as situações nas quais a aproximação entre o habitus dos dois produtores de imagens não acontece ou não pode ser estabelecida de forma imediata. ${ }^{5} \mathrm{~A}$ grande contribuição da iconologia de Panofsky - que, salvo algumas exceções, não foi introduzida nas Ciências Sociais e na Educação - foi justamente sua revelação do habitus, ou seja, do "sentido do ser" (Wesenssinn) e do sentido documentário (de um período histórico como o Renascimento, por exemplo), através de analogias ou homologias entre diferentes mídias e diferentes formas de representação de uma época: da literatura à pintura e arquitetura não deixando escapar a música.

No entanto Max Imdahl (entre outros: 1979, 1994 e 1996) parte justamente dessa contribuição expressiva de Panofsky para lançar um questionamento sobre o que permanece relevante na imagem enquanto mídia, ou seja, o que, nas interpretações de Panofsky ainda pode ser encontrado a respeito da iconicidade. Panofsky não está interessado no conteúdo (Sinngehalt) transmitido somente pela imagem, mas sobretudo naqueles que também podem ser transmitidos através da imagem, mas não unicamente.

5 Um exemplo da incongruência entre o habitus do produtor que reproduziu a imagem e os produtores reproduzidos na imagem representa, por exemplo, o retrato de uma família do sertão nordestino tomado pelo fotógrafo Sebastião Salgado e que recebeu o título "Família com onze filhos no sertão do Tauá, Ceará. 1983" (in: Salgado, Sebastião. Terra. Frankfurt/M., 1997 apud Bohnsack, 2003, p. 249-257). 
Nesse contexto, Imdahl critica ainda a reduzida significação atribuída por Panofsky à forma e à composição da imagem que teriam sido reduzidas à função de proporcionar o reconhecimento de sua composição natural e de suas narrações iconográficas (por exemplo: de textos históricos sobre a cura ou de passagens narradas na Bíblia). Ao invés da redução ao "olhar que reconhece" (wiedererkennendes Sehen), Imdahl propõe o "olhar que olha" (sehendes Sehen), ou seja, o olhar que considera a totalidade ou a integralidade da imagem e não somente suas particularidades. A crítica de Imdahl a Panofsky também pode ser explicada pelo fato de que Panofsky, ao questionar o como da produção ou formação dos conteúdos dos objetos e de seu modus operandi, o faz tardiamente e somente a partir do nível iconográfico no qual a informação já foi apreendida através de elementos verbais ou textuais. Já a interpretação icônica de Imdahl parte do nível pré-iconográfico, principalmente da composição formal da imagem. De acordo com Imdahl, a interpretação icônica pode manter-se distante do pré-conhecimento iconográfico ou dos sentidos atribuídos ao iconográfico. Ela pode, "à exceção da percepção literária ou do conteúdo cênico da imagem, ser bem sucedida justamente quando o conhecimento sobre o sujeito representado é, por assim dizer, metodologicamente posto de lado" (Imdahl, 1996, p. 435). Este tipo de procedimento é necessário quando se busca apreender a imagem no sentido proposto por Imdahl, ou seja, como "um sistema evidente na construção de suas normas imanentes e em sua autonomia" (Imdahl, 1979: 1906), ou ainda como um "sistema autopoético", para utilizarmos um termo da moderna teoria dos sistemas de Niklas Luhman (1990).

É possível traçar aqui alguns paralelos entre Panofsky e a semiótica com seus dois proeminentes representantes: Umberto Eco e Roland Barthes. Apesar das respectivas diferenças, ambos os autores estão de acordo quan-

6 Orig.: "Ein nach immanenten Gesetzen konstruierten und in seiner Eigengesetzlichkeit evidentes System". 
to à necessidade de nos colocarmos aquém do nível conotativo a fim de melhor explicitar a singularidade e a particularidade da imagem (cf. Bohnsack, 2003b). O nível conotativo pode ser compreendido - e isto é salientado de forma explícita por Umberto Eco (1994, p. 242) - em alguns aspectos, como análogo ao nível iconográfico de Panofsky. A singularidade e a particularidade da imagem em relação ao texto, ou seja, a especificidade da mensagem gráfica do signo icônico (ikonisches Zeichen) se apresentam de maneira diferenciada no nível denotativo ou pré-iconográfico. No processo de decodificação da mensagem gráfica é necessário deter-se primeiramente na análise dos códigos conotativos ou iconográficos. Nesse sentido, em um primeiro momento, no nível do senso comum, tendemos a construir mentalmente ações ou histórias relativas a essas imagens não-abstratas, por exemplo, situações específicas que eventualmente ocorreram no momento da produção da imagem. A decodificação de toda e qualquer mensagem que, por sua vez, só pode ser transmitida através da imagem é então "liberada" [orig.: "débarassée"] como diria Barthes (1990, p. 37), pelo seu código conotativo ou iconográfico. Este percurso transforma a imagem "em um resto de mensagem, aquilo que sobra depois de terem sido dissipados os signos da conotação" (Barthes, 1982, p. 347).

Neste aspecto, também podemos estabelecer um paralelo com a interpretação realizada por Foucault, da pintura "Las Meninas" de Velásquez quando ele acentua que "é preciso, pois, fingir não saber quem se refletirá no fundo do espelho e interrogar esse reflexo no nível de sua existência" (Foucault, 1999, p. 12). Foucault não está defendendo a omissão do conhecimento institucionalizado, do conhecimento adquirido sobre relações e papéis sociais específicos (neste caso, o conhecimento relativo à Corte enquanto instituição, às damas da corte, aos cortesãos, os anões). Trata-se,

7 Orig.: c'est d'abord, si l'on veut, un message privatif, constitué par ce qui reste dans l'image lorsque'on efface (mentalement) les signes de connotation" 
acima de tudo, da necessidade de "pôr de parte os nomes próprios" - como afirma Foucault (ibidem) -, de excluir o conhecimento relativo à especificidade da pessoa retratada e de sua história concreta quando o intérprete pretende "manter aberta a relação entre a linguagem e o visível ... [quando] quiser falar não de encontro a, mas a partir de sua incompatibilidade" (ibidem).

Nas considerações a seguir, pretendemos demonstrar algumas concordâncias existentes entre proeminentes princípios e tradições da interpretação da imagem. Estes aspectos em comum estão relacionados à necessidade de colocarmos "entre parênteses" alguns conteúdos específicos, relativos ao nível conotativo ou iconográfico e fortemente influenciados pelas narrações verbais, ou seja, pelo conhecimento textual. Esse procedimento é necessário se quisermos manter o princípio da abertura - como diria Foucault (1971, p. 38) - na (tensa) relação entre imagem, fala e o respectivo texto e se quisermos evitar que a imagem seja ordenada sob a lógica falada-textual desde o início. Esse procedimento ainda não foi levado suficientemente em consideração no âmbito dos métodos qualitativos. No que tange à semiótica, Roland Barthes desenvolveu interpretações exemplares com base no princípio do "colocar entre parênteses" o pré-conhecimento relativo à imagem, situação esta que é possível "quando apagamos (mentalmente) os signos conotativos" (1982, p. 34 ${ }^{8}$ ). Barthes definiu o resultado advindo desta interpretação como sentido obtuso (sens obtue). O significado deste nível de sentido é ambíguo e contraditório quando formatado pela fala ou pelo texto. Tomando como exemplo fotos do filme "O couraçado Potemkin" de Eisenstein, Barthes demonstra, por exemplo, que a mímica do choro de uma velha não é nem uma 'mímica trágica' quando interpretada em seu sentido mais simples e tampouco uma 'comédia'.

8 Orig.: "lorsqu'on efface (mentalement) les signes de connotation". 
De modo semelhante ao que foi proposto por Barthes, Imdahl (1994, p. 300) percebe a especificidade do sentido icônico como sendo a "complexidade de sentido do contra-sobreposto"9 (op cit, 1996a: 107). Com base no afresco "A captura de Cristo" de Giotto, Imdahl esclarece que - da forma como a imagem foi concebida -, Jesus é retratado simultaneamente como dominante e dominado (1994, p. 312):

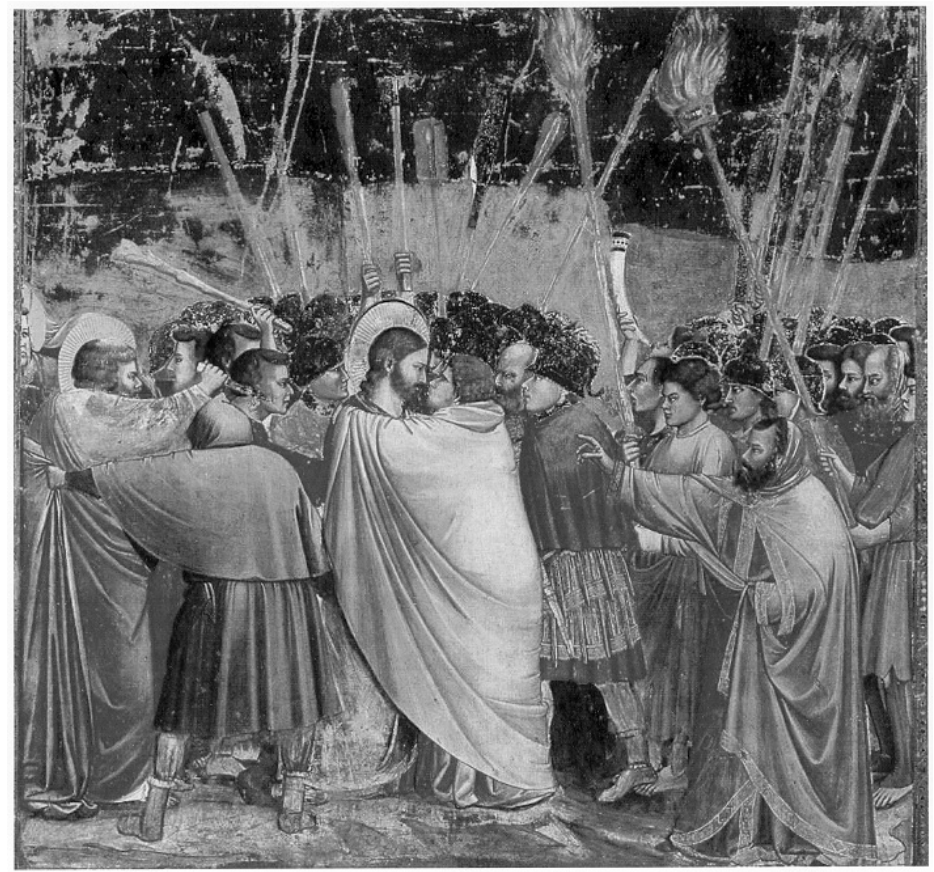

"A captura de Cristo" de Giotto di Bondone (1266-1337)

9 Orig.: Die "Sinnkomplexität des Übergegensätzlichen". 
Esses complexos conteúdos estão relacionados à composição planimétrica da imagem pelo fato de a mesma não apresentar profundidade na criação da perspectiva. De acordo com Imdahl, a composição da imagem é definida, sobretudo pela linha diagonal oblíqua. A complexidade dos significados sobrepostos dificilmente é apreendida verbalmente, e a compreensão do sentido da linguagem intersubjetiva só é possível a partir da visualização da imagem. Enquanto a verbalização desses complexos significados por meio da simplificação iconográfica não é vista como totalmente inútil por Imdahl, Barthes pondera que o sentido obtuso pode ser "situado teoricamente, mas não descrito" (1982, p. 58 $\left.{ }^{10}\right)$. Em outras palavras: "o sentido obtuso não está na fala" (op. cit.: $53^{11}$ ).

Um método de interpretação de imagens, capaz de transcender o nível superficial dos sentidos conotativo ou iconográfico, parece não ser possível a partir da semiótica de Roland Barthes. Já o desenvolvimento de um método de interpretação de imagens - a partir de Panofsky e Imdahl , parece-nos possível, embora exista a necessidade de algumas precisões metodológicas, particularmente no que diz respeito ao colocar entre parênteses o sentido conotativo ou iconográfico, o conhecimento verbal ou textual adquirido previamente. Essas precisões metodológicas são de fundamental importância, sobretudo no processo de interpretação de imagens no campo das Ciências Sociais e da Educação, uma vez que a iconografia não é apresentada de forma codificada, como acontece, por exemplo, na história da arte cujas imagens remetem, em muitos casos, a textos religiosos oriundos da Bíblia.

Como dito anteriormente, Foucault destaca não ser necessário apagar todos os a - priori conceituais, todos os nomes, mas tão somente os nomes próprios ou sobrenomes. A exemplo da fotografia de uma família, o apagar

10 Orig.: "que l'on peut situer théoretiquement mais no décrire".

11 Orig.: "Le sens obtue n'est pas dans la langue". 
dos nomes próprios possibilita ao intérprete, por meio de fontes seguras ou de suposições, a elaboração da premissa de que as pessoas ali retratadas compõem uma família, gerando, desta forma, uma espécie de atualização de seu conhecimento relativo à instituição família. Caso o intérprete saiba ou suspeite que a fotografia em questão retrata a família Meyer, deve colocar entre parênteses todo e qualquer conhecimento biográfico sobre a família. Estas duas formas de conhecimento podem ser definidas com base no método documentário de interpretação como conhecimento comunicativo e conhecimento conjuntivo.

O conhecimento comunicativo diz respeito ao conhecimento generalizado e muitas vezes estereotipado: são os conhecimentos institucionalizados. As instituições - no sentido atribuído por Berger \& Luckmann (1998) - são encontradas nos esquemas que apresentam uma tipificação recíproca entre as ações incorporadas e os tipos de atores. Já o conhecimento conjuntivo, subjacente aos nomes próprios, é um conhecimento sobre a família Meyer, relativo às particularidades individuais e específicas assim como às características típicas do meio social. Mesmo estando de posse de um pré-conhecimento sobre a biografia da familia, adquirido, por exemplo, através de entrevistas ou de análises de conversação, este deve ser suspenso no momento de análise da fotografia.

A interpretação deverá ser iniciada em um estágio aquém do nível iconográfico, ou seja, no nível pré-iconográfico situado na análise da estrutura formal da imagem. Imdahl distingue três dimensões da estrutura formal ou composição formal da imagem:

- a estrutura planimétrica total (planimetrische Ganzheitsstruktur),

- a coreografia cênica (szenische Choreographie),

- a projeção perspectivista (perspektivische Projektion).

A projeção perspectivista visa identificar a espacialidade e a corporalidade dos objetos. Ela está, por assim dizer, orientada para a análise 
do mundo externo retratado na imagem. Com relação à coreografia cênica, esta seria equivalente à ambientação que ocorre em uma cena social. Em contrapartida, a composição planimétrica, ou seja, a construção formal da imagem no nível plano, objetiva captar a imagem como "um sistema evidente na construção de suas normas imanentes e em sua autonomia" (Imdahl, 1979: 190). Enquanto tendemos - no nível do senso comum - a retirar da imagem cada um de seus elementos constitutivos, a reconstrução da composição formal, sobretudo da estrutura planimétrica, nos leva a interpretar os elementos não mais de forma isolada, mas enquanto conjunto e em cor-relação aos demais elementos da composição.

Também no âmbito da interpretação de textos é necessário considerar a totalidade do contexto produzido pelo escritor. Os métodos qualitativos recorreram, em parte, à lingüística ou sociolingüística para assim garantir a integridade e reconstrução formal da estrutura. De forma análoga, os métodos de interpretação de imagens nas Ciências Sociais e na Educação devem levar em consideração os desenvolvimentos formais da Estética e da História da Arte. Neste sentido, o cientista da educação Klaus Mollenhauer afirma serem "apenas as características formais estéticas as que explicitam o conteúdo. Dito mediante uma metáfora lingüística: a sintaxe da imagem indica à semântica da imagem o seu caminho" (1983, p. 179). Na medida em que conseguimos - com a ajuda da estrutura formal, entre outros apreender a imagem como um sistema singular ou auto-referente, nos é aberto também um caminho que leva à compreensão da especificidade do espaço de experiências conjuntivas dos produtores de imagens, por exemplo, ao sistema familiar e seus habitus familiares específicos.

Como ilustração, apresentaremos a seguir um exemplo advindo de um projeto sobre "Tradierungsprozessen in Familien" (Processos de perpetuação de tradições famíliares), cujo material empírico consiste em fotografias de familiares, conversações na hora das refeições, que foram gravadas pe- 
los membros das famílias e grupos de discussão. ${ }^{12}$ Trata-se especificamente de uma fotografia tomada por ocasião da primeira comunhão na antiga Alemanha Oriental no início dos anos 1980.

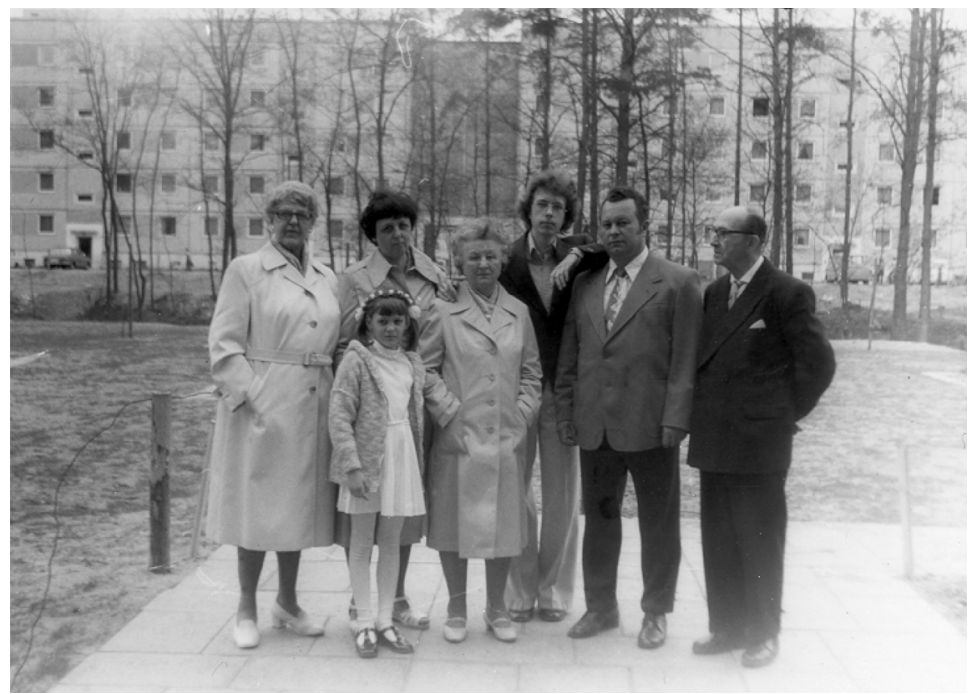

Família Schiller oriunda da antiga Alemanha Oriental Fonte: Arquivo de imagens do autor

A composição planimétrica é determinada pelas linhas horizontais e verticais. As pessoas responsáveis pela produção desta imagem - tanto os representantes ou fotógrafos como os que nela foram representados - escoIheram compor a imagem utilizando a geometria do caminho de pedestres, localizado no primeiro plano, e a verticalidade das árvores ao fundo. Essa estruturação vertical-horizontal da fotografia domina a fotografia em sua

12 Para maiores detalhes sobre o respectivo projeto, bem como análises de outras fotografias cf. Bohnsack 2001b e 2003c. 
totalidade, conferindo-lhe uma ordenação formal e rígida. Nela estão expressos ainda elementos importantes relativos ao meio social familiar, seus espaços sociais de experiências e vivências.

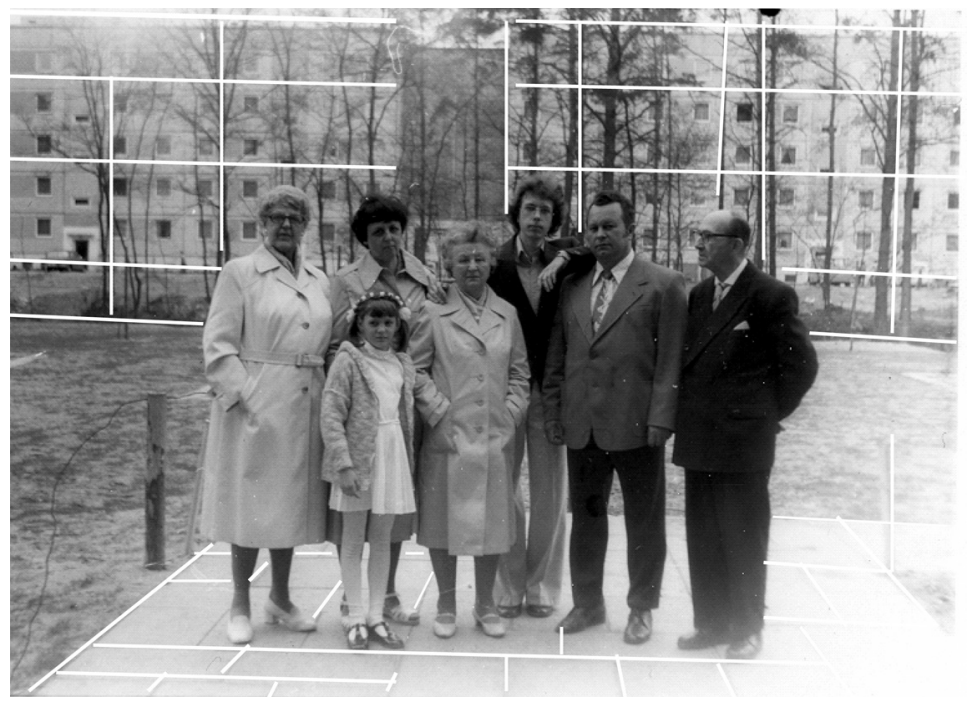

Família Schiller oriunda da antiga Alemanha Oriental

Fonte: Arquivo de imagens do autor

Entretanto a rigidez e a formalidade produzem um contraste com o caráter provisório do que se encontra em primeiro plano: o caminho de pedestres em sua incompletude, parecendo não conduzir a lugar algum. Esse caráter de incerteza e incompletude é acentuado pela falta de um segundo plano na imagem e ainda, pelo fato de o terceiro plano encontrarse bastante recuado. O pequeno grupo parece, desta forma, estar um tanto quanto isolado, descontextualizado e distanciados de suas relações cotidianas. Parecem estar um tanto perdidos. Esta relação um tanto quanto intrigante entre o caráter provisório e incerto do isolamento (social) do grupo, 
por um lado, e, por outro, a rigidez e a formalidade (não só do ponto de vista planimétrico da imagem, mas também da postura corporal, dos gestos e das mímicas), promove a principal impressão da imagem e revela algumas características do habitus familiar. Trazendo para o formato verbal ou textual, esse habitus pode ser meramente formulado como uma contraposição recíproca (Übergegensätzlichkeit), como habitus da rigidez e da formalidade em um contexto provisório e inseguro. Como apresentado anteriormente, a especificidade do sentido icônico encontra-se - para Imdahl - na "complexidade do sentido contraposto" (Sinnkomplexität des Übergegensätzlichen), algo claro e evidente na imagem, mas de difícil explicitação verbal ou textual.

Retornando à estrutura formal da imagem, é preciso levar em conta que, além da composição planimétrica, é sobretudo a projeção perspectivista, ou seja, a perspectividade da imagem que deverá constituir-se como objeto da análise. A perspectiva permite, como a própria palavra indica, o desenvolvimento de uma perspectiva sobre os produtores de imagens e suas visões de mundo. A fotógrafa responsável pela produção da imagem posicionou-se "olho a olho" com a avó. O ponto de fuga, resultante desta estruturação da perspectiva, não toma a criança que festejava sua primeira comunhão como alvo, mas a sua avó, trazendo para o centro da imagem uma hierarquia geracional e de gênero, típica para a família Schiller. De forma homóloga a essa estruturação estabelecida pela produtora da imagem (a fotógrafa), também a organização dos membros da família - do grupo dos produtores reproduzidos na imagem - se dá em torno da avó. Esta hierarquia familiar específica, pautada nas relações geracionais e de gênero observadas na fotografia, foram constatadas posteriormente nas análises dos textos relativos às conversações gravadas no momento das refeições, bem como das entrevistas realizadas com os membros da família. 


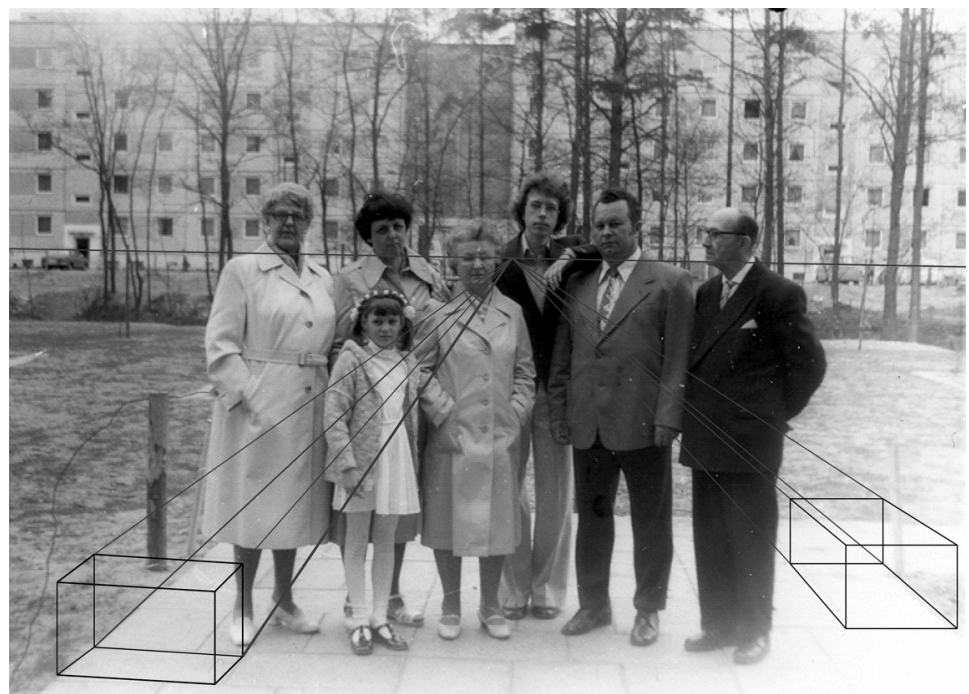

Família Schiller oriunda da antiga Alemanha Oriental Fonte: Arquivo de imagens do autor

De acordo com Imdahl (1996), o acesso ao sentido estrutural particular de uma imagem só é possível se a estrutura simultânea for apreendida a partir da composição formal como uma "composição que introduz simultaneamente um sentido próprio", no qual "o todo (...) é concebido de antemão como uma presença total" (p. 23). Este aspecto representa uma diferença central em relação aos métodos qualitativos de interpretação de textos, nos quais a análise seqüencial constitui uma das principais ferramentas, quando não chega a ser o princípio metodológico principal (Sacks, 1995). Quando este princípio é aplicado à análise de imagens, a especificidade da mesma - como apontado por Imdahl - passa despercebida, algo que também se aplica à análise de vídeos (cf. Wagner-Willi, 2006). Se efetuarmos uma observação metodológica acurada da relação entre a análise seqüencial 
e a análise da estrutura simultânea, veremos que os dois caminhos de análise remetem a um princípio ainda mais geral: o da operacionalização de diferentes horizontes ou, em outras palavras, o princípio da análise comparativa. Por exemplo, a estrutura específica de um discurso ou de uma narração só será apreendida a partir do contraste e comparação de diferentes discursos ou narrações (cf. entre outros: Bohnsack, 2001c). Também na análise de imagens, regida pelo princípio da análise de estruturas simultâneas, é necessário realizar esse trabalho de comparação com outros horizontes. Como demonstrado por Imdahl, a apreensão da especificidade da composição formal de uma imagem só é possível a partir da comparação com outras composições contingentes (kontingenter Kompositonsmöglichkeiten). Essas outras possibilidades podem ser criadas mentalmente de forma experimental ou - e ainda melhor - por meio de horizontes comparativos empíricos, por exemplo, de outras fotografias relativas ao evento em questão (primeira comunhão), que poderão ser introduzidas no processo de interpretação. Esta mudança experimental da composição, assim como a introdução da comparação com base em outros exemplos empíricos, diferenciados entre si pela variação sistemática da composição, foi por nós denominada como "variação da composição" (cf. Bohnsack, 2001b). O princípio da análise comparativa também pode ser encontrado nas interpretações iconológicas ou documentárias de Panofsky (1953). Por exemplo, para chegar a uma definição do espírito da época "Quattrocento" do século $\mathrm{XV}$, o autor examinou obras dessa época com base no princípio do contraste máximo, comparando pinturas italianas e pinturas flamengas em relação ao que elas, apesar dos contrastes, tinham em comum (cf. Bohnsack, 2003b). Este procedimento é semelhante ao desenvolvido para a interpretação de textos e que corresponde ao princípio do "contraste entre o que é comum ou do que é comum no contraste ${ }^{13 "}$ (cf. Bohnsack, 2001c e 2001d)

13 Orig.: "Das Prinzip des Kontrasts in der Gemeinsamkeit bzw. der Gemeinsamkeit im Kontrast". 
A relação entre a análise seqüencial e a análise comparativa, ou seja, a mudança da perspectiva analítica da pergunta o quê para a pergunta como, assim como a importância do conhecimento implícito e da interpretação fundamentada na estrutura formal, indicam ser possível desenvolver princípios metodológicos ou parâmetros comuns para a análise de textos e de imagens, sem deixar de lado as características e especificidades da imagem e do texto (cf. Bohnsack, 2005). Através do método documentário de interpretação ${ }^{14}$, buscamos trazer uma contribuição nesse sentido.

\section{Referências}

BARTHES, Roland. Der entgegenkommende und der stumpfe Sinn. Kritische Essays III. Frankfurt a. M.: Suhrkamp, 1990.

BARTHES, Roland. Lóbvie et Lóbtue. Essais critiques III. Paris: Éditions du Seuil, 1982.

BARTHES, Roland. Eléments de sémiologie. In: . OEuvre complètes. Paris: Éditions du Seuil, 1993, p. 1467-1542.

BERGER, Peter L.; LUCKMANN, Thomas. A construção social da realidade (16 $\underline{a}$ Ed.). Petrópolis: Vozes, 1998.

BOHNSACK, Ralf. Die dokumentarische Methode in der Bild- und Fotointerpretation. In: Ralf Bohnsack; Iris Nentwig-Gesemann; Arnd-Michael Nohl (Hrsg.): Die dokumentarische Methode und ihre Forschungspraxis. Grundlagen qualitativer Sozialforschung. Opladen: Leske/Budrich, 2001a, p. 67-89.

BOHNSACK, Ralf. „Heidi“: Eine exemplarische Bildinterpretation auf der Basis der dokumentarischen Methode. In: Ralf Bohnsack; Iris Nentwig-Gesemann; ArndMichael Nohl (Hrsg.): Die dokumentarische Methode ... Opladen: Leske/Budrich, 2001b, p. 323-337.

14 No Brasil, são poucos os trabalhos sobre o método documentário de interpretação. Para maiores informações sobre esse procedimento de análise, cf. Weller, 2005. 
BOHNSACK, Ralf. Dokumentarische Methode. Theorie und Praxis wissenssoziologischer Interpretation: In: Theo Hug Hrsg.): Wie kommt Wissenschaft zu Wissen? - Band 3: Einführung in die Methodologie der Sozial- und Kulturwissenschaften. Baltmannsweiler: Schneider-Ver. Hohengehren, 2001c, p. 326-345.

BOHNSACK, Ralf. Typenbildung, Generalisierung und komparative Analyse. Grundprinzipien dokumentarischer Interpretation. In: Ralf Bohnsack; Iris NentwigGesemann; Arnd-Michael Nohl (Hrsg.): Die dokumentarische Methode ... Opladen: Leske/Budrich, 2001d, p. 225-252.

BOHNSACK, Ralf. Rekonstruktive Sozialforschung - Einführung in qualitative Methoden (5 ${ }^{\underline{a}}$ Aufl.). Opladen: Leske/Budrich, 2003a.

BOHNSACK, Ralf. Qualitative Methoden der Bildinterpretation. In: Zeitschrift für Erziehungswissenschaft (ZfE), Heft 2, p. 159-172, 2003b.

BOHNSACK, Ralf (2003b): Exemplarische Bildinterpretationen. In:

Rekonstruktive Sozialforschung. Einführung in qualitative Methoden ( $5 \stackrel{\mathrm{a}}{\mathrm{Aufl}}$.). Opladen: Leske/Budrich, 2003c, p. 236-257.

BOHNSACK, Ralf, Standards nicht-standardisierter Forschung in den Erziehungsund Sozialwissenschaften. In: Zeitschrift für Erziehungswissenschaft (ZfE), 7. Jg., Beiheft Nr. 3, p. 65-83, 2005.

BOURDIEU, Pierre. Der Habitus alsVermittlung zwischen Struktur und Praxis. In: 125-158.

. Zur Soziologie symbolischer Formen. Frankfurt a.M.: Suhrkamp, 1970, p.

BOURDIEU, Pierre. Entwurf einer Theorie der Praxis auf der ethnologischen Grundlage der kabylischen Gesellschaft. Frankfurt a.M.: Suhrkamp, 1976.

BOURDIEU, Pierre. Die Praxis der reflexiven Anthropologie. In: Bourdieu, Pierre; Wacquant, Loïc. Reflexive Anthropologie. Frankfurt a.M.: Suhrkamp, 1996.

ECO, Umberto. Einführung in die Semiotik (8. Aufl.). München, 1994.

FOUCAULT, Michel. As palavras e as coisas. São Paulo: Martins Fontes, 1999.

GARZ, Detlef; KRAIMER, Klaus. Die Welt als Text. Theorie, Kritik und Praxis der objektiven Hermeneutik. Frankfurt a. M.: 1994.GOFFMAN, Irving. Stigma. Notes on the Management of Spoiled Identity. Englewood Cliffs N. J., 1963. 
IMDAHL, Max. Überlegungen zur Identität des Bildes. In: Marquard, Odo; Stierle, Karlheinz (Hrsg.): Identität (Reihe: Poetik und Hermeneutik, Bd. VII). München, 1979, p. $187-211$.

IMDAHL, Max. Bilder und ihre Anschauung. In: Gottfried Boehm (Hrsg.): Was ist ein Bild?. München. 1994, p. 300-324

IMDAHL, Max. Giotto - Arenafresken. Ikonographie - Ikonologie - Ikonik. München, 1996.

LUHMANN, Niklas. Die Wissenschaft der Gesellschaft. Frankfurt a. M.: Suhrkamp, 1990.

MANNHEIM, Karl. Beiträge zur Theorie der Weltanschauungsinterpretation. In: . Wissenssoziologie. Neuwied, p. 91-154 [Original: 1921-1922 in: Jahrbuch für Kunstgeschichte XV, 4].

MANNHEIM, Karl. On the interpretation of Weltanschauung. In:

Essays on the sociology of Knowledge. London: Routledge \& Kegan Paul, 1952, p. 33-83.

MANNHEIM, K. Strukturen des Denkens. Frankfurt/M.: Suhrkamp, 1980 [inglês: Structures of Thinking. Collected Works Volume Ten. London: Routledge \& Kegan Paul, 1982].

MOLLENHAUER, Klaus. Streifzug durch fremdes Terrain. Interpretation eines Bildes aus dem Quattrocento in bildungstheoretischer Absicht. In: Zeitschrift für Pädagogik. 30.Jg., Heft 2, p. 173-194, 1983.

MOLLENHAUER, Klaus. Methoden erziehungswissenschaftlicher Bildinterpretation. In: Friebertshäuser, Barbara; Prengel, Annedore (Hrsg.): Handbuch qualitative Forschungsmethoden in der Erziehungswissenschaft. Weinheim: 2003, p. 247264.

MICHEL, Burkard. Bildrezeption als Praxis. Dokumentarische Analyse von Sinnbildungsprozessen bei der Rezeption von Fotografien. In: ZBBS (Zeitschrift für qualitative Bildungs-, Beratungs- und Sozialforschung). Heft 1, p. 67-86, 2004.

MICHEL, Burkard. Bild und Habitus. Sinnbildungsprozesse bei der Rezeption von Fotografien. Wiesbaden: VS Verlag, 2006.

MITCHELL, William J. T. Picture Theory. Essays on Verbal and Visual Representation. Chicago \& London, 1994. 
PANOFSKY, Erwin. Zum Problem der Beschreibung und Inhaltsdeutung von Werken der Bildenden Kunst. In: Logos, XXI, 1932, p. 103-119 [reeditado em: Aufsätze zu Grundfragen der Kunstwissenschaft. Berlin, 1964, p. 85-97].

PANOFSKY, Erwin. Die Perspektive als „symbolische Form“. In: Aufsätze zu Grundfragen der Kunstwissenschaft. Berlin, 1964, p. 99-167.

PANOFSKY, Erwin. Ikonographie und Ikonologie. Eine Einführung in die Kunst der Renaissance. In: _. Sinn und Deutung in der bildenden Kunst. Köln, 1975, p. 36-67 [Original: 1955: Meaning in the Visual Arts. New York].

PANOFSKY, Erwin. Early Netherlandish Painting. Cambridge/Mass.: Harvard University Press, 1953.

POPPER, Karl. The Logig of Scientific Discovery. London: Hutchinson, 1959.

REICHERTZ, Jo. Der morgen danach. Hermeutische Auslegung einer Werbefotografie in zwölf Einstellungen. In: Hartmann, Hans A.; Haubl, Rolg (ed). Bilderflut und Sprachmagie. Fallstudien zur Kultur der Werbung. Opladen, p. 141-163.

REICHERTZ, Jo. Objective Hermeneutics and Hermeneutic Sociology of Knowledge. In: Flick, Uwe; von Kardorff, Ernst; Steinke, Ines (ed.). A companion to qualitative research. London: SAGE, 2004, p. 290-95

RICOEUR, Paul. Der Text als Modell hermeneutisches Verstehen. In: Gadamer, Hans-Georg; Boehm, Gotfried (Hrsg.). Seminar: Die Hermeneutik und die Wissenschaften. Frankfurt a. M.: Suhrkamp, 1978, p. 83-117.

RORTY, Richard. The linguistic Turn: Recent Essays in Philosophical Method. Chicago: University Press of Chicago, 1967.

SACKS, Harvey. Lectures on Conversation. Volumes I+II. Oxford, UK/Cambridge, USA, 1995.

SCHÜTZ, Alfred. Collected Papers I: The Problem of Social Reality. Den Haag, 1962.

WAGNER-WILLI, Monika. On the multidimensional analysis of video data: documentary interpretation of interactions in schools. 2006 (mimeo). 
WELLER, Wivian et al. Karl Mannheim e o método documentário de interpretação: uma forma de análise das visões de mundo. Sociedade e Estado, v. XVII, n. 02, p. 375-396, jul./dez. 2002.

WELLER, Wivian. A contribuição de Karl Mannheim para a pesquisa qualitativa: aspectos teóricos e metodológicos. Sociologias, v. 7, n. 13, p. 260-300, jan./abr. 2005. 


\section{Resumo}

O considerável desenvolvimento dos métodos qualitativos durante os últimos vinte anos está intrinsecamente relacionado à "virada lingüística" (linguistic turn). A presunção de que textos gravados constituem os dados básicos em todas as pesquisas científicas é conseqüentemente responsável por esta predominância dos métodos de interpretação de textos e por esta "fixação" particular sobre os textos no âmbito das metodologias qualitativas. No entanto é preciso estabelecer uma diferença entre a comunicação sobre (über) a imagem e a comunicação através (durch) da imagem. O acesso metodológico à compreensão pre-conceptual ou 'ateórica' foi introduzido, nos anos 1920, pela iconologia de Erwin Panofsky e pelo seu contemporâneo Karl Mannheim com seu método documentário de interpretação. Importantes correspondências entre ambas abordagens, assim como em relação ao campo da semiótica podem ser demonstradas. Com base no discernimento de que o caráter icônico em sua obstinação não nos é acessível de forma adequada pela linguagem, podemos concluir - pautados nos autores acima, assim como em Barthes, Focault e Imdahl -, que a apreensão das peculiaridades de uma imagem implica em uma suspensão, em um "colocar entre parênteses" as nossas conotações (fundamentadas no pré-conhecimento iconográfico mediado pela linguagem) tanto quanto possível. Metodologicamente, o caráter icônico só pode ser reconstruído através da descrição da forma, sobretudo de estrutura planimétrica da imagem. O método documentário de interpretação de imagens é um procedimento apropriado para o enfrentamento deste desafio.

Palavras chave: Interpretação de imagens, método documentário, métodos qualitativos, Erwin Panofsky, Karl Mannheim.

Recebido: 15/08/06

Aceite final: 23/11/06 